\title{
A Framework for e-Learning Resources Sharing (FeLRS)
}

\author{
Philip O. Ayoo and Jude T. Lubega
}

\begin{abstract}
Educational resource sharing is emerging as a viable means to improve the quality of and access to education. By pooling resources and taking advantage of each other's expertise, learning providers could build adequate capacity and reduce costs, tap into the resources that they do not have and participate in a networked resource development process. This paper describes an on-going study that was undertaken to explore the feasibility of sharing electronic educational resources within higher education. It takes the case of universities in East Africa, and proposes a Framework for e-Learning Resources Sharing (FeLRS) that is expected to maximize the utilization of available e-learning resources for academic and research purposes. Two case studies are undertaken to collect data from a sample of universities in five countries, and descriptive statistics is used to analyze and present the data. Unified Modeling Language (UML) is used to provide the notation for describing the processes which are logically grouped into two general scenarios - laying foundation for e-resources sharing, and implementation arrangements for e-resources sharing. The resultant framework is described showing the relationships between the various processes that lead to e-learning resources sharing. These main processes include establishing demand for e-resources, harmonisation of policies and processes, resources mobilization, developing ICT human resources capacity, establishing physical infrastructure, maintaining adequate e-resources, and creating awareness for e-resources.
\end{abstract}

Index Terms-E-learning, resources sharing, UML modeling, information systems.

\section{INTRODUCTION}

The development of pervasive computing and Internet technologies is making learning more and more ubiquitous, happening on demand, anytime and anywhere [1]. At the same time, more and more instructional resources are produced, delivered and stored in digital form, with the annual growth rate of global digital information exceeding $60 \%$ at present [2]. One of the most interesting scenarios is that a lot of these resources are free for use and sharing. Despite the resources being open source, access to them has still remained less especially in the developing countries. Most of these resources are unknown, since they are scattered across different learning platforms, websites and teachers' personal computers, and adhere to different technical standards, which makes the aggregation, reuse and sharing of digital learning resources difficult. Under such context, how to organize learning resources to support anytime, anywhere, on demand and adaptive learning is an emerging problem.

Manuscript received June 15, 2013; revised September 17, 2013.

Philip O. Ayoo is with Makerere University, Uganda (e-mail: payoo@iucea.org).

Jude T. Lubega is with Uganda Technology and Management University (UTAMU), Uganda.
Educational resource sharing is emerging as a viable means to improve the quality of and access to education. By pooling resources and taking advantage of each other's expertise, learning providers could build adequate capacity, reduce redundancy in infrastructure and reduce costs. The design plan of distributed heterogeneous educational resources sharing platform can realize the inter-connection, inter-communication and sharing, reduce the cost of education information and speed up the process of access to resources for teaching and learning [3]. Consequently, the time and cost that would have been incurred by an institution is sharable amongst the partners through a give and take commitment. This is the reason why several countries have adopted the norm of being part of educational networks and associations.

This paper describes an on-going study that was undertaken to explore the feasibility of sharing electronic educational resources within higher education. It takes the case of universities in East Africa, and proposes a Framework for e-Learning Resources Sharing (FeLRS) that is expected to maximize the utilization of available e-learning resources for academic and research purposes. This has been done by presenting a brief review of the literature to identify what is going on in this area. The methodology used in the study is then explained, followed by detailed presentation and discussion of study findings. The design of the framework is then provided in the next section, and finally recommendations and conclusions of the study are given.

\section{LITERATURE REVIEW}

Traditional education models will no doubt be unable to achieve educational empowerment effectively in the emerging knowledge societies. Learning is one of the crucial fields of activity that have benefited from exponential technological development [4]. According to [5], the reasons for the increasing interest in virtual education distil down to the achievement of one or more of three basic objectives: one, to increase access to learning opportunities by enhancing the flexibility of delivery modes or by eliminating geographic barriers to participation; two, to enhance the quality of the learning experience in terms of content or pedagogy; and three, to enhance institutional efficiency by reducing costs, increasing productivity or increasing market share. ICTs provide an array of powerful tools that may help in transforming the present isolated, teacher-centred and text-bound classrooms into rich, student-focused, interactive knowledge environments [6]. Consequently, e-learning is increasingly being suggested as an alternative to, or a way to enhance, traditional educational approaches since it can overcome many of the challenges involved in reaching underserved students. e-Learning is defined as a wide set of 
applications and processes which use all available electronic media to deliver education and training, including computer-based learning, web-based learning, virtual classrooms and digital collaboration and uses [7]-[9].

Current trends in e-learning recognize that each individual student will have different requirements and characteristics [8]. Therefore, in order to support different teaching and learning paradigms, e-learning should deal with more than simply reading online lessons; content as well as communication and collaboration have to be supported in a highly personalised manner by e-learning systems [10]. Current trends also show that online learning will be increasingly diverse to respond to different learning cultures, styles, and motivations. Personalisation and adaptivity will continue to be key issues in modern e-learning environments as they improve the knowledge acquisition process [10].

To facilitate online learning, various learning management systems (LMS) have been developed and are being used. In general terms, the goal for both commercial and custom-built LMS is the same: to provide a medium by which course materials can be delivered and accessed in a web-based platform as well as provide the technology medium for interaction among a learning community [11]. To better serve this purpose, course management systems are continually undergoing further development to increase the effectiveness of the system in meeting the needs of institutions at which these applications are in use. In order to improve their design, there is need for regular evaluation to assess the extent to which they continue to meet the goals of learning.

However, the power of e-learning is more than technology; it includes the social dynamics of networking. The revolutionary impact of e-learning lies not simply in having a multimedia platform on a single desktop. It is the combined power of a worldwide network of such computers - that connects authors, instructors and learners globally - with the immediacy of text, graphics, audio and video, as well as interactivity and collaborative sharing. Therefore, as learning programmes move to the online environment, it is essential to develop ways to encourage and facilitate collaboration and cooperation [12].

Resources sharing refers to the use of learning resources (course content, research, learning management systems, etc) in digital format by different learners located in more than one educational institution. However, sharing e-learning resources efficiently and effectively is a challenge. One barrier is that currently available resources have not been described accurately and do not readily interoperate [13]. In this context, collaborations can reduce costs associated with designing and implementing commonly used e-learning platforms and courses (i.e. sharing of reusable learning objects housed in a common repository). It is therefore important that frameworks are explored on how best the sharing of these educational resources may be made possible.

\section{Methodology}

To investigate the present research problem, a methodology consisting of four steps was developed. The first stage involved an in-depth literature study, including review of existing research data to understand the e-learning and resource sharing environment with respect to the state-of-the-art in e-learning research. The second stage of the study included the empirical research, in which two case studies were conducted to analyse the existing environment for provision of e-learning and resource sharing within universities in East Africa (Burundi, Kenya, Rwanda, Tanzania and Uganda). The first case study assessed the general ICT environment in the universities, while the other case study examined the learning environment more closely, with respect to the provision of e-learning and the need to share e-resources amongst universities. Structured interviews were used to collect data from a sample of universities within the five partner states of the East African Community. The third stage of the study consisted of presentation and discussion of the empirical results of the studies, based on the results from the case studies, resulting in a list of requirements for developing a framework for sharing e-resources. Descriptive statistics have been used to present and analyse data, with charts and bar graphs forming the main data presentation tools.

Finally, the fourth stage involved the design of the framework based on the list of requirements. UML (Unified Modeling Language) has been used to provide the notation for describing and managing the diagram-based object-oriented modelling. The processes are logically grouped into two general scenarios - laying foundation for e-resources sharing, and implementation arrangements for e-resources sharing - whose modelling is then described. For each of these scenarios, the following are constructed: use-case diagram, activity diagram, and sequence diagram. A component diagram is then constructed that brings together all the components that form the framework, plus the relationships between them.

\section{PRESENTATION AND Discussion OF FindingS}

The findings of the empirical study helped in coming up with a list of requirements that would go into designing the framework. Key results from the main areas that were investigated are presented and discussed in the sections that follow.

\section{A. Areas of ICT Application within Universities}

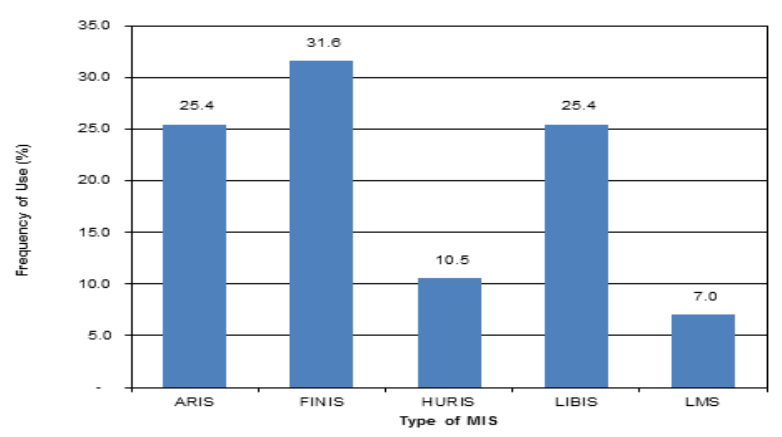

Fig. 1. Management information systems (MIS) implemented at universities in East Africa.

Majority of the management information systems (MIS) implemented within universities in East Africa were aimed at streamlining the financial management function (31.6\%), followed by academic register and library management 
(25.4\% each). Implementation of systems for managing human resources (at 10.5\%) was just slightly higher than learning management systems (7\%) (Fig. 1).

Fig. 1 above shows that most of the universities were still utilizing ICT mainly for administrative purposes (FINIS, ARIS, LIBIS, HURIS). Use of ICT for teaching, learning and research was just being introduced (7\% for LMS). Therefore, there is need for awareness creation and to bring out a strong justification for integrating e-learning within universities.

\section{B. ICT Infrastructure}

Infrastructure is a key determinant of the extent to which ICT may facilitate the achievement of the goals of universities, and its development has been a major preoccupation of many higher education institutions in east Africa. Infrastructure was assessed through the level of accessibility to ICT facilities, availability of networks, and relevant software. Out of the 52 universities surveyed, only 12 universities $(23 \%)$ reported computer-student ratios of 1:10 (one computer for 10 students) or lower. The computer-staff ratios were slightly better in most universities, with 10 universities $(19.2 \%)$ reporting a ratio of $1: 1$ (one computer per member of staff).

When it came to networking, $42.3 \%$ of universities had local area networks (LANs) in all buildings, 23.1\% had LANs in most buildings, while $28.8 \%$ had LANs in some (few) buildings (Fig. 2). Further to this, $76.9 \%$ of the universities had implemented campus-wide backbone networks connecting their LANs. For multi-campus networking, $23.1 \%$ of the universities reported to have backbone networks connecting their various university campuses.

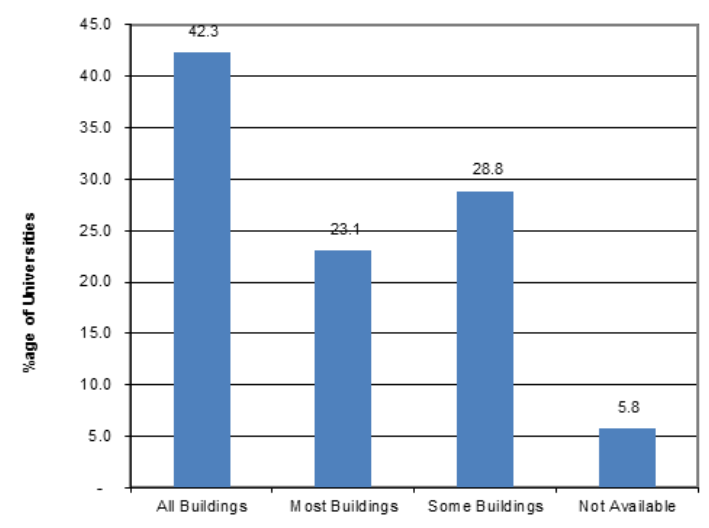

LAN Availability

Fig. 2. Local area networking within universities in East Africa.

On Internet access, the three oldest public universities in East Africa (Dar es Salam, Makerere, Nairobi) were still leading in the aggregate amount of bandwidth purchased. Apart from the three universities above - Makerere $(25 \mathrm{mb})$, Nairobi (14mb), Dar es Salaam (11 mb) - and Kenyatta (5mb), all the other universities had bandwidth capacities below $5 \mathrm{mb}$. The bandwidth per capita shows that access to bandwidth for serious research and academic pursuits is still elusive for all universities in East Africa. Thus, due to the critical role played by physical infrastructure in facilitating access and enabling e-resources sharing, there is need to make sure that ICT infrastructure is prioritized in the academic institutions so as to facilitate the sharing of e-learning resources.

\section{Planning and Monitoring Tools}

About $65 \%$ of the universities in East Africa had ICT policy plans while $21 \%$ were in the process of developing such plans (see Fig. 3).

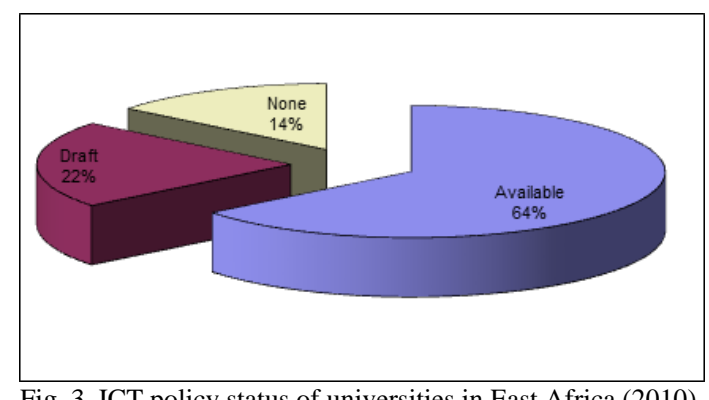

Fig. 3. ICT policy status of universities in East Africa (2010).

In most universities, however, issues relating to e-learning were addressed in other strategic documents, especially the ICT policy plan or the overall university strategic plan. Only one university had an e-learning strategic plan - National University of Rwanda. There is therefore critical need for universities to develop policies aimed at mainstreaming ICT in teaching and learning through development of e-learning strategies. These strategies would need to be harmonised so as to enable sharing of resources. This is a critical component to streamline how things are done by institutions which are interested in undertaking e-learning resource sharing.

\section{Availability of e-Resources}

Various electronic resources are available in universities, including e-content (books, library catalogs, databases, etc), research (publications, projects, theses and dissertations), technology (hardware, bandwidth, systems/software), expertise (staff, skills), policies (internal/external), etc. However, less than two-thirds of the university libraries in East Africa were automated, with public access catalogs (OPAC) available at different levels: $23.1 \%$ of libraries had web-based OPACs accessible over the Internet; $19.2 \%$ of the OPACs could only be accessed within the university intranet; while $21.2 \%$ of the OPACs were available only within the library LAN. Furthermore, most universities relied on external information resources with $75 \%$ of them subscribing to international journals.

Whereas access to library materials is key for teaching/learning and research, the fact that only about $23.1 \%$ of the university libraries had web-based online public access catalogues (OPACs) means that resources of most universities are not readily available to the wider academic and research community. It should therefore be noted that the basic requirement for resources sharing is to have documents in electronic formats, which unfortunately is presently not the case for most universities in East Africa. Therefore, availability of e-resources in suitable formats would be critical in implementing the sharing framework.

\section{E. Human Resources Capacity Development in ICT}

The study established that $61.5 \%$ of universities in East Africa provided ICT training at the undergraduate level, $15.4 \%$ at the masters level and $9.6 \%$ at the doctorate level (Fig. 4). In addition, there were several diploma courses 
provided by $30.8 \%$ of universities, plus $23.1 \%$ of universities providing professional certifications on vendor products such as CISCO, Microsoft, and Oracle, as well as a number of certificate courses.

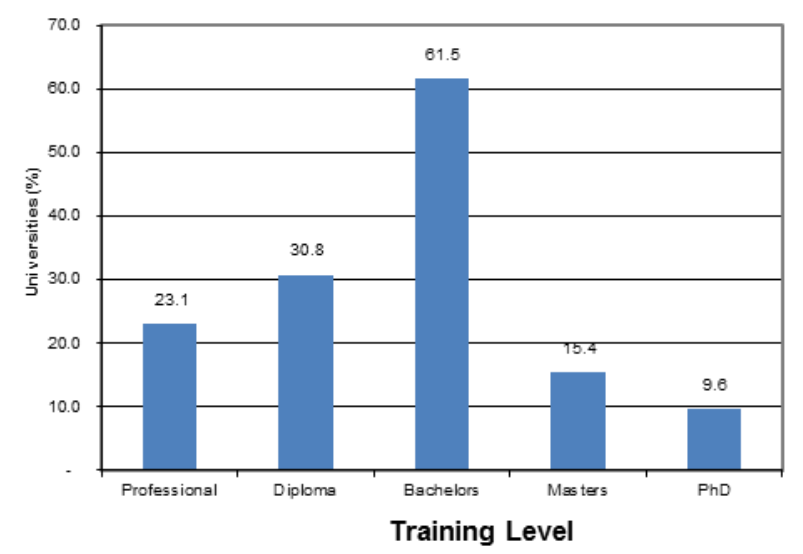

Fig. 4. ICT training within universities in East Africa.

Whereas technical ICT skills were readily available for technical staff, there was lack of skills in e-learning pedagogy, instructional design, animation, graphic design, web design, and LMS support. At the same time, e-learning skills were still not well understood to enable appropriate development of technical staff. It is therefore necessary to build ICT human resources capacity that can sustain the e-learning resources development and sharing.

\section{F. ICT Financing}

The study established that various models existed for allocating ICT budgets within universities in East Africa: centralized budget for ICT, separate budgets per unit or department, and a mixed model. Most of the resources for ICT were from the university coffers, and this was not adequate to meet the needs. Given the key role ICT plays in the university, it is no longer responsible to budget for it in an ad hoc manner and to fund it on a crisis basis. Therefore, the aspect of resources mobilization becomes important.

\section{G. Coordination of e-Resources Sharing}

Several scenarios were considered on how to administer the sharing of e-resources. One was to implement a common LMS in a central location and have it mirrored on agreed sites. Alternatively, participating institutions would use their various LMS and allow access to them for other participating institutions. Respondents, however, expressed a strong desire for a central/regional body to coordinate the partnership, and come up with a policy to enable sharing, which must address e-content development and implementation in member universities. Therefore effective coordination of an e-learning resource sharing environment is critical for such a network to happen.

In anticipation of the need to design a framework for e-learning resources sharing, several requirements were extracted from analysis of the above findings. It was apparent that for sharing to happen smoothly within institutions of learning, there was need to undertake the following: awareness creation, ICT infrastructure development, harmonisation of policies and processes, availability of sharable e-resources, development of human resources in
ICT, mobilization of resources, and effective coordination.

\section{FRAMEWORK DESIGN}

Based on the above requirements emanating from the study findings, the design of the framework has been logically divided into two general scenarios whose modelling is then described. The first scenario involves laying the foundation for e-resources sharing, which includes the following processes: improving physical infrastructure, creating awareness for e-resources sharing, harmonisation of policies and processes, and maintaining adequate e-resources. The second scenario describes activities on implementation arrangements for e-resources sharing, which includes the following processes: developing ICT human resources capacity, resources mobilization for ICT, and coordination and administration.

Through a logical design, the two scenarios were described using different models to illustrate how the interaction of key actors - including librarians, e-learning and e-content experts, ICT and training experts, policy makers, researchers, project experts, governments, financiers, coordinating agencies and other stakeholders - undertake their different roles. Each of these two scenarios, plus their corresponding processes, is described in the following sections.

\section{A. Laying Foundation for e-Resources Sharing}

In this section, the first scenario of the system has been modelled through use-case diagrams (Fig. 5) to describe functionality of the system from the point of view of external users (called actors). In order to elaborate the use-cases, activity diagrams have been used, showing the set of actions and the order in which actions take place, identifying the outcomes and how one action could lead to another, and emphasizing on the object's flow of control by capturing these as activities. The processes are then described briefly.

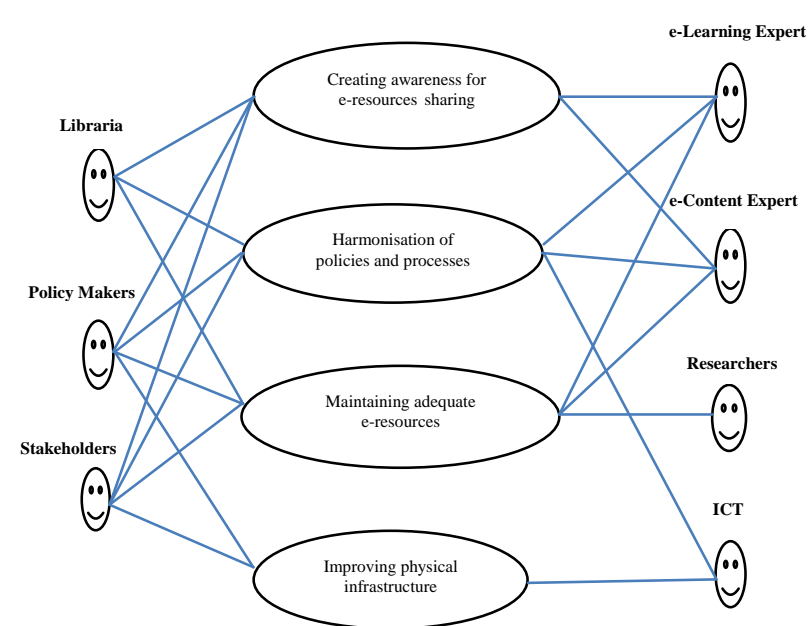

Fig. 5. Use-case diagram on laying foundation for e-resources sharing.

This use-case diagram shows how various actors interact with four processes that are important in laying the foundation for e-resources sharing, namely creating awareness for e-resources sharing, harmonization of policies and processes, maintaining adequate e-resources, and improving physical infrastructure. These processes are crucial in ensuring that e-resources sharing is firmly 
grounded and sustained. The activity diagram that follows (Fig. 6) shows exactly how these processes are linked to one another and how they are undertaken to ensure achievement of the goal of sharing e-resources. The processes involved are then explained in the subsequent paragraphs.

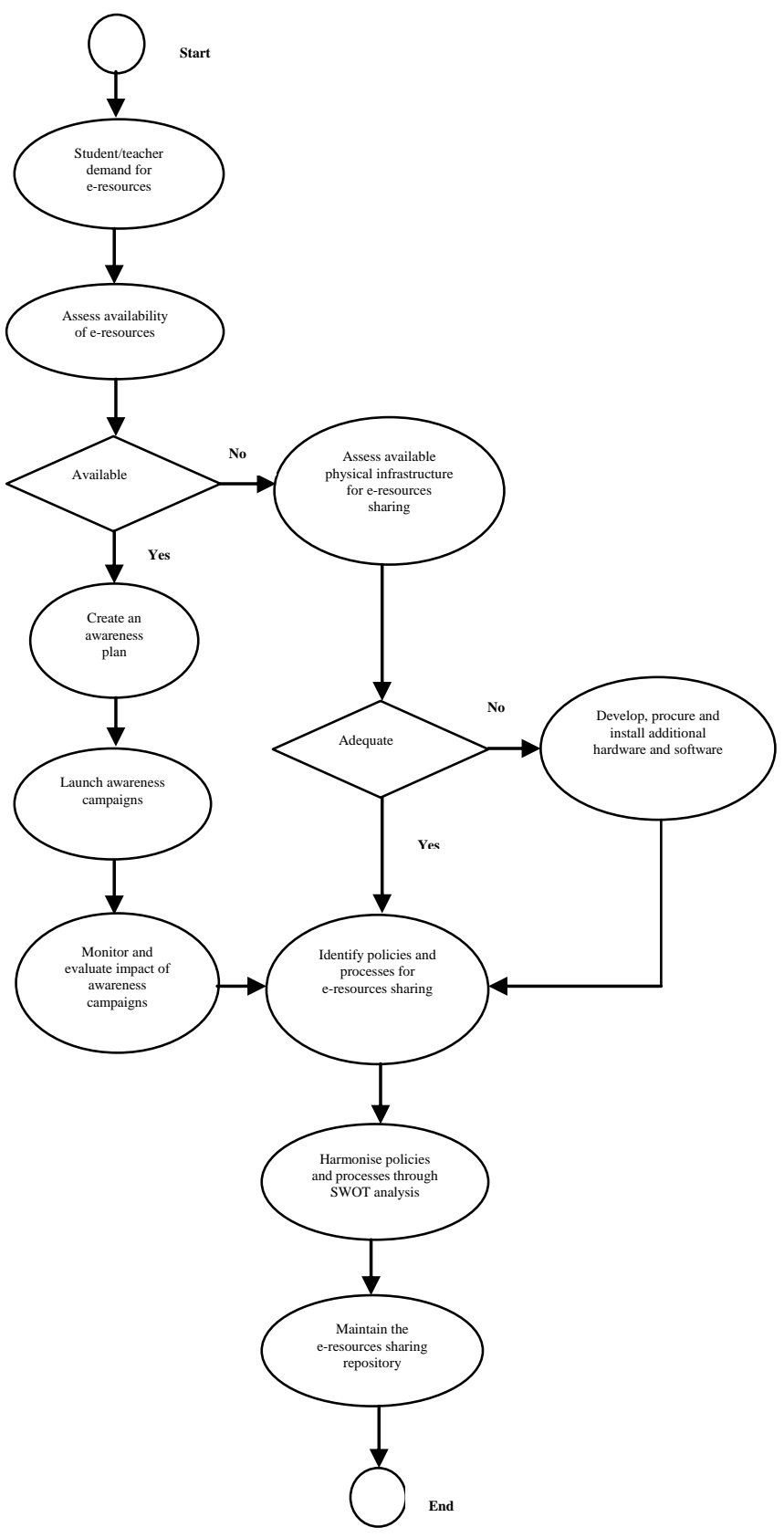

Fig. 6. Activity diagram on laying foundation for e-resources sharing.

Demand for e-resources by Users. The process starts with a learner or faculty demanding information resources to satisfy some identified learning/teaching or research need. This demand may come in various forms: a student or faculty may make a request for particular resources to a librarian or to an information system. At the same time, a student may make a request to faculty member for particular learning content.

Assess availability of e-resources. Once a request is received, the librarian or faculty will search for the information resource in the library collection, retrieve it and submit it to the user. Accessibility and usability of electronic information is more valuable when it is readily available in the required electronic formats at the time it is required. However, in case this resource is not available in the library, the librarian will search other sources, including other libraries and databases in order to arrange for it to be transmitted to the user.

Assess available infrastructure. In case the resource is available in electronic format, there must be some level of infrastructure that would allow it to be retrieved, including Internet connection. This component would therefore seek to establish what exists in terms of computer laboratories, extent of local and wide area networking, Internet connectivity and capacity, learning management systems, e-content development multimedia studios, etc.

Develop, procure and install additional hardware and software. Each university must plan, design, implement, and maintain modern ICT infrastructure that provides an enabling environment for provision of quality e-learning services to the users. This component would therefore involve identification, procurement, installation and configuration of required hardware and software, networks and Internet connectivity. It would also involve development of strategies for maintenance and sustainability of these resources.

Develop awareness creation plan. One of the factors that may influence the success of e-learning initiatives is the amount of awareness of its benefits and related factors. Development and implementation of a good awareness or sensitization plan would raise the awareness in the institutions, and enlighten staff and management on the importance of introducing ICT in the development of the educational process. The awareness plan would clearly identify the key stakeholders to be targeted, their awareness needs, and the resources required to implement the plan.

Launch awareness campaigns. The objective here would be to sensitize staff and students on the benefits of e-learning and the need to share e-learning resources. Suitable awareness creation channels- including sensitization and awareness creation workshops, public lectures, seminars and conferences - will be identified and held in universities in a bid to demystify e-learning, change management, change attitude and bring all staff and students on board for e-learning resources sharing. At the same time, an e-learning incentive or reward scheme would be established for the most proficient e-learning faculty and students.

Monitor and evaluate impact of awareness campaigns. As an integral part of day-to-day operational management to assess progress against objectives, monitoring will support effective management of the awareness campaigns through reports on actual performance against what was planned or expected. Evaluation, on the other hand, would provide credible and useful information with a view to determine the worth or significance of the undertaking, incorporate lessons learned into decision-making and enhance the overall quality of the awareness campaigns.

Identify policies and processes for e-resources sharing. Every university has some policies that act as guides in various aspects of its operations, and these would need to be identified. Especially important here are policies governing the nature of ownership, contribution and compensation for those who develop e-learning resources. Clear policies on intellectual property rights (IPR), such as copyright and 
ownership, would remove the considerable confusion, which is acting as a barrier to gaining the benefits of sharing and re-use.

Harmonize policies and processes. Due to the extensive growth in the use of online resources and materials in learning and teaching, institutional policies and processes may need updating to take into account the corresponding changes in management approach and systems provision. The empirical study established that many of the policies and processes utilized within universities in East Africa were not in harmony with each other. There would therefore be need to harmonise administrative, financial, educational, research, legal, ethical, security and sharing policies and processes. This would then remove the bottlenecks that inhibit resources sharing caused by conflicting policies and process within individual institutions.

Assess available e-resources. Implementation of a framework for sharing resources is only appropriate if there are resources to share. A deliberate effort must therefore be expended to identify all available resources in order to device ways of enabling access to them by learners and researchers in the region. Through this assessment, resource gaps could be established and a mechanism put in place to develop resources where they are found to be inadequate.

Maintain e-resources sharing repository. Progress shown by universities in digitizing their local content is a great leap in availing content to their colleagues and to the world. The need therefore for institutional repositories to house the digitized content for easy access and use becomes important. However, for the resources to be meaningful and helpful to the users, especially content for pedagogical purposes, there is need for them to be developed within a framework that facilitates learning. For this reason, a framework must be put in place to guide the development of constructivist e-learning resources and systems.

B. Implementation Arrangements for e-Resources Sharing

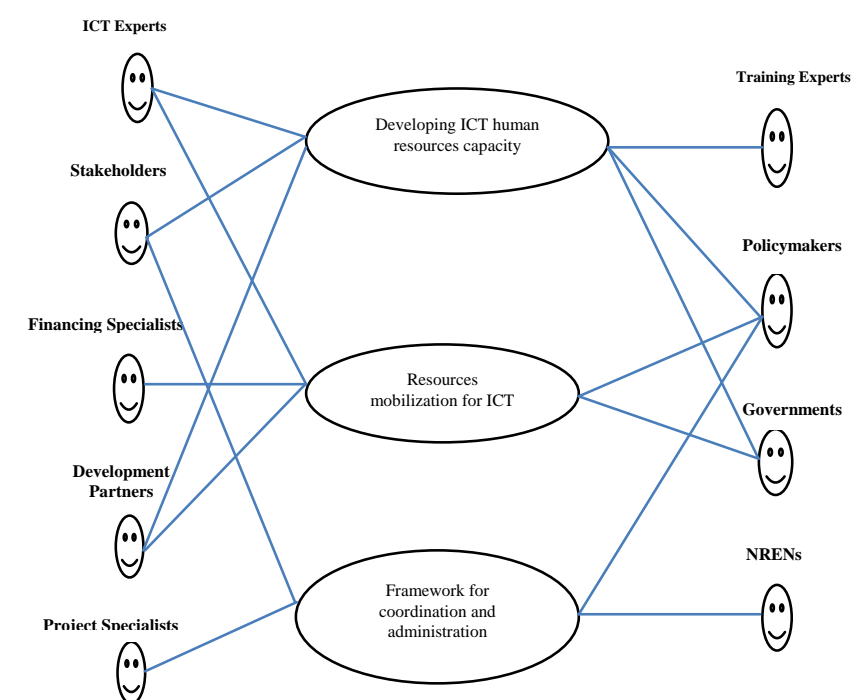

Fig. 7. Use-case diagram on implementation arrangements for e-resources sharing.

In this section, the second scenario of the framework has been modeled by giving details of the subsequent three processes, namely, developing ICT human resources capacity, resources mobilization for ICT, and coordination and administration.
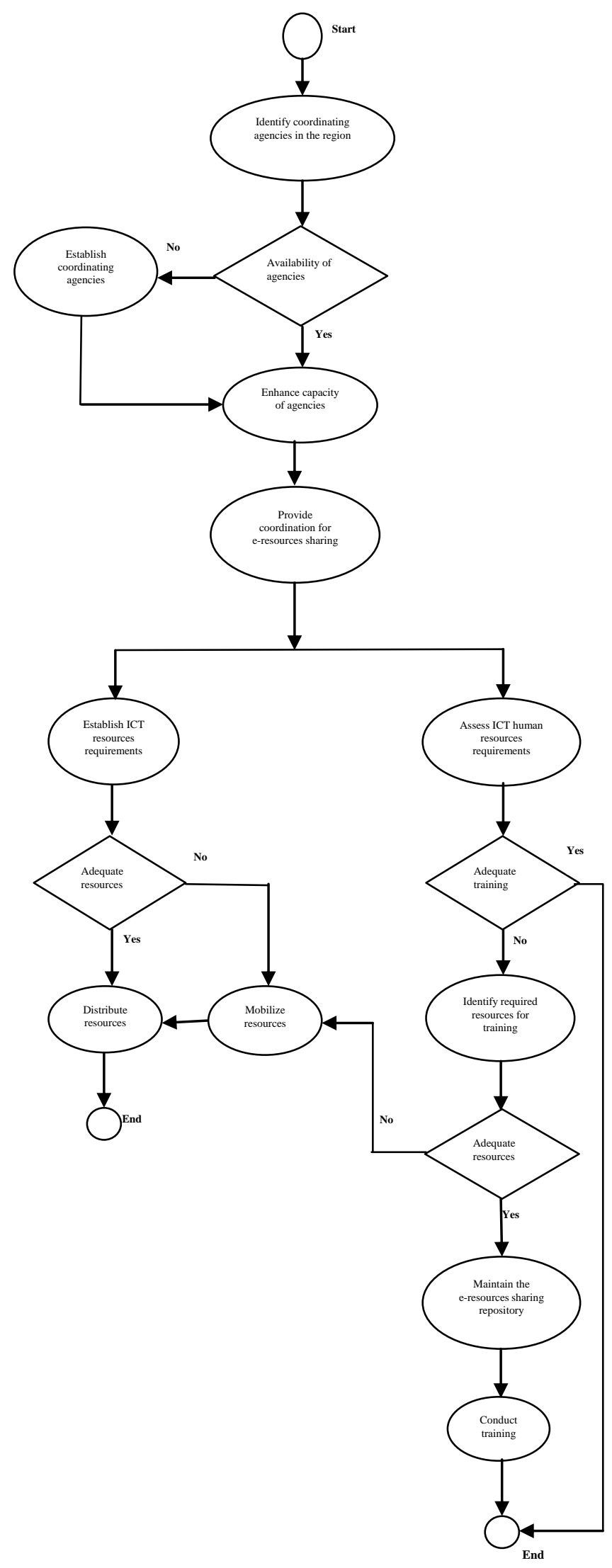

Fig. 8. Activity diagram on implementation arrangements for e-resources sharing.

This second use-case diagram (Fig. 7) shows how various actors interact with the last three processes that are crucial in 
implementation of e-resources sharing. The subsequent activity diagram (Fig. 8) shows exactly how these processes are linked to one another, and an explanation is given of exactly what each process entails.

Assess ICT human resources requirements. The study has established that inadequacy in external and internal training programmes for critical skills to manage and support ICT functions have led to inadequate human resources and skills base for implementation of technical ICT projects. This further limits the introduction and utilization of ICTs for academic and research purposes. To address this need, universities need to continuously train their staff in existing and emerging educational technologies to provide them with functional skills for effective utilization of these technologies in their day-to-day activities. This component would require that a comprehensive study is undertaken to identify the gaps that currently exist within university academic staff in functioning effectively in the digital age. The needs assessment exercise would be used to identify the areas in which academic staff require training in order that they are able to use ICT tools more effectively in teaching and research.

Develop ICT training programmes to address the needs. The information on training requirements is used in developing an appropriate curriculum for training academic staff in the use of ICT. This curriculum is validated and used to conduct training for staff of universities. Especially for those faculty members who do not have proper background in education as a discipline, they would need training on pedagogical ICTs, including curriculum development and upgrading. However, before the training is executed, appropriate content is developed for the training curriculum.

Establish ICT resources requirements. Financial and other resources are key ingredients to e-learning resources sharing. An e-learning resources needs assessment would provide information on the resources required for e-learning, their availability and existing resource gaps. Some of the key areas that would need to be sustained through resource mobilization from within and outside the university include: physical infrastructure in terms of buildings and/or renovation of existing ones to house e-learning and multimedia equipment; provision of ICT and e-learning infrastructure; provision of equipment for e-learning (including hardware and software); capacity building for teaching and technical staff; and e-content development.

Establish sources of funding. The aim of this activity is to identify the possible funding sources that should be pursued. A resources mobilization strategy is key as such a plan would be useful in identifying opportunities that can be approached in a strategic and systematic way. The resources mobilization strategy would further assist in the identification of potential sources of funding. It is most likely that resources would be sought from multiple sources to cover different interventions within the strategic plan.

Mobilize and distribute resources. Various techniques would then be employed to mobilize the required resources as specified in the strategic plan. One of the tools used to mobilize resources would be the development of funding proposals. Good proposal writing would depend on having a clear, credible vision, and a well-defined implementation plan. The resources would then have to be distributed to the areas where they are most needed. These areas would already have been identified within the strategic plan.
Identify coordinating agencies. Resources sharing require a coordinating agency to provide a 'clearing house' role, and this may be provided at various levels: institutional, national and regional. There would be need for the development of clear criteria for selecting the various levels of coordination that would provide for a proper coordination and administrative framework. At the institutional level, for instance, each university would be expected to coordinate e-learning activities within its various academic units. At the national level, on the other hand, there already exist the national research and education networks (NRENs) that act as national clearinghouses for universities in the respective countries. Finally, there would be need for a regional consortium to propel e-resources sharing by streamlining information gathering, storage, dissemination and use amongst the universities within the region.

Establish and enhance capacity of coordinating agencies. Strategies to strengthen NRENs could be in terms of regulatory support and in funding capital development of their networks, as well as human capacity development to enable them execute their work in a professional way for the benefit of stakeholders in the region. At the same time, appropriate equipment would need to be put in place to facilitate the coordinating role of the agencies. Policies and operational frameworks would be developed, including clear terms of reference to guide work of the coordinating agencies.

\section{Frameworkfor e-Learning Resources Sharing (FeLRS)}

Having considered the two scenarios and the different processes entailed within each of them, it was apparent that for clarity purposes, all the components are joined to form the framework. Figure 9 describes the resulting framework that can easily be adopted for sharing educational resources within higher institutions of learning. It should be noted that the components are considered sequentially and results from one component feed into the others.

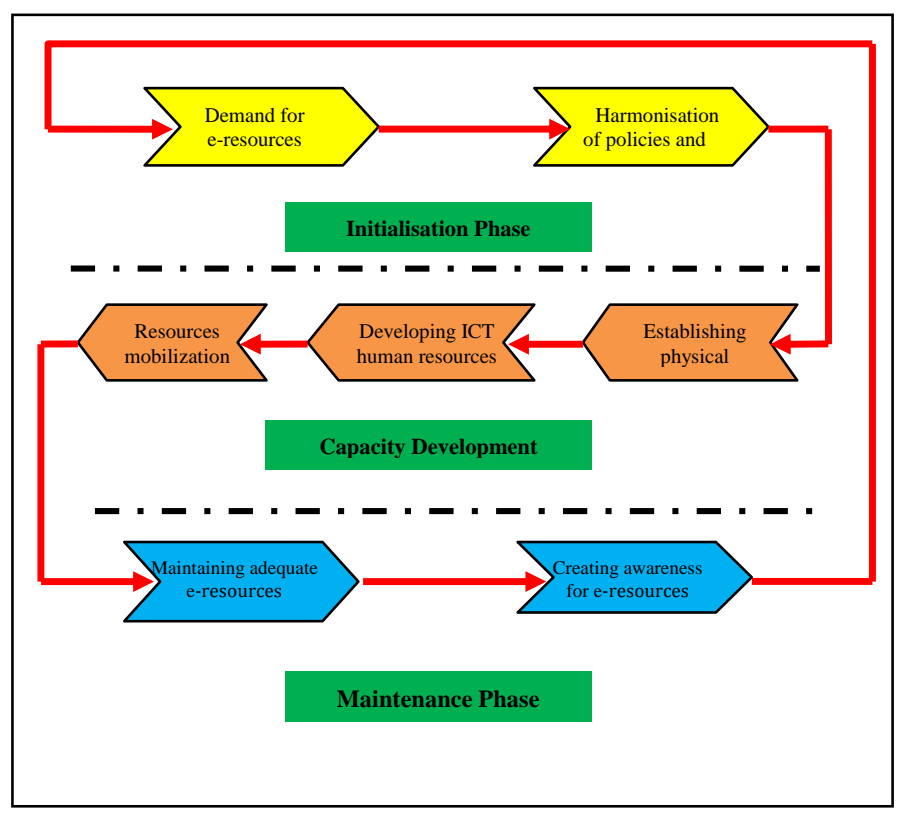

Fig. 9. Framework for e-Learning Resources Sharing (FeLRS).

The framework addresses seven processes that are divided into three phases, namely initialisation, capacity development, and maintenance. The initialisation phase deals with the processes that are basic to the commencement of the sharing 
phenomenon, including establishment of demand for e-resources and harmonisation of policies and processes. The capacity development phase aims at putting in place resources and capabilities that would facilitate the sharing of e-resources, including the development of suitable physical infrastructure (hardware and software), developing needed human resources capacity (especially in ICT), and mobilizing resources for implementation of the framework. Finally, the maintenance phase deals with issues relating to proper functioning of the processes and their continued sustainability, where key processes include maintenance of adequate e-resources and awareness creation.

\section{RECOMMENDATIONS AND CONCLUSION}

As has been observed, an e-learning resources sharing framework is only applicable if there are resources to share. These sharable resources must be developed in a way that facilitates learning, by subscribing to the constructivist paradigm, which focuses on the need for the learner to take full control of their learning. The content must be intelligent, and the design must borrow from the reusable learning object concept. Multimedia content can easily be shared through the framework by first optimizing the content to different types as noted by [14]. Once content has been transformed into the type needed, it can easily be shared through any type of bandwidth. In coming up with the system, the designer must consult with stakeholders in the learning environment, including the learners, tutors, instructional designers, and system administrators in charge of the online learning management systems.

Furthermore, resource sharing requires a coordination framework that would provide a 'clearing house' role. This coordination would best be achieved if there is a regional framework that is already in place with appropriate mandate for the region. At the national level, the existing National Research and Education Networks aim to unite local universities for the purpose of sharing research and educational resources through the exiting collaborative engagements. These NRENs can provide a basis for further sharing of resources in other aspects including e-learning, and must therefore be strengthened.

It is expected that through the sharing of e-learning resources, inequity amongst universities could be minimised. Within this arrangement, however, it would be essential that all universities have access to at least a common base of collaborative technologies such as web access and e-mail. Additionally, more advanced collaboration technologies should be introduced and systematically deployed at the universities.

\section{REFERENCES}

[1] S. Yu, "Research on the organization model of ubiquitous learning resource - the concept and architecture of learning cell," in Proc. the IASTED International Conference on Technology for Education and Learning, Beijing, China, October 2011, pp. 24-25.

[2] Y. Bing and S. Congkai. (2011). Exploration and innovation in e-learning resource center construction. Journal of Distance Education in China. [Online]. Available: http://en.crtvu.edu.cn/index.php?option=com_content\&view=article\& id $=556 \&$ Itemid $=198$

[3] R. Changquan, L. Xuefeng, W. Yukuo, and Z. Yanhong, "The design and implement of educational resource sharing platform based on web service," in International Forum on Information Technology and
Applications (IFITA), Shanghai, 16-18 July 2010, vol. 3, no. 1, pp. 323-326.

[4] N. Daoudi and R. Ajoun "Pedagogy centered on Learner in E, M and P-Learning Continuum: Active and Situated Learning," vol. 3 no. 3, pp. 358-361, Jun. 2013.

[5] F. Tilya, N. Moens, and N. Ducastel, "ICT in education: the Tanzanian experience," International Institute for Communication \& Development: The Hague, NL, 2006.

[6] E. I. Omwenga and A. Rodrigues, "Towards an education evaluation framework: synchronous and asynchronous e-learning cases," Journal of the Research Centre for Educational Technology, vol. 2, no. 1, 2006.

[7] S. Kakoty, M. Lal, and S. Sarma, "E-learning as a research area: an analytical approach," International Journal of Advanced Computer Science and Applications (IJACSA), vol. 2, pp. 144-148, 2011.

[8] N. Sivakumar, K. Vivekanandan, and S. Sandhhya "Incorporating agent technology for enhancing the effectiveness of e-learning system," IJCSI International Journal of Computer Science Issues, vol. 8, issue 3, no. 1, May 2011, ISSN: 1694-0814.

[9] S. Marshall and G. Mitchell, "Potential indicators of e-learning process capability," presented at EDUCAUSE Conference, Adelaide, Australia, 6-9 May, 2003.

[10] C. Gütl, V. M. Garcia-Barrios, and F. Mödritscher, "Adaptation in e-learning environments through the service-based framework and its application for AdeLE, in Proc. ELEARN 2004, Washington, 2004, p. 1891-1898.

[11] J. T. Abbitt, "Developing an evaluation framework for a custom-designed course management system," Journal of Interactive Online Learning, vol. 5, no. 2, pp. 193-216, 2006.

[12] P. B. Gill, R. B. Sherman, and G. B. Linn, "Developing a collaborative culture in on-line learning," International Journal of Information and Education Technology, vol. 3, no. 3, pp. 333-336, 2013.

[13] S. Yang, M. Joy, and J. R. C. Nurse, "Experiences on Sharing eLearning Resources using Service Technologies," in Proc. Computers and Advanced Technology in Education, Cambridge, UK, 11 - 13 July 2011.

[14] N. A. Suhail, J. Lubega and G. Maiga, "Multimedia to Enhance Blended Learning Experience in Constrained Low Bandwidth Environment," in Lecture Notes in Computer Science, S. Cheung, J. Fong, L. Kwok, K.. Li, and R. Kwan, Ed., Berlin Heidelberg: Springer-Verlag, 2012, pp. 317-328, vol. 7411.

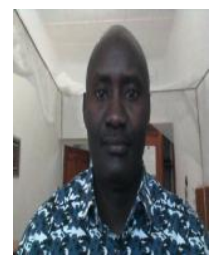

Philip O. Ayoo is a $\mathrm{PhD}$ candidate in information systems at Makerere University, Uganda, born in Kisumu, Kenya on June 16 1970. He holds a Bachelor of Science degree (Information and Media Technology) from Moi University, Kenya (1995) and a Master of Philosophy degree in Information Sciences (Library and Information Studies) from the same university (2001). $\mathrm{His} \mathrm{PhD}$ thesis is entitled "A framework for developing and sharing constructivist e-learning resources."

Since September 2000, he has been working as the Electronic Database Specialist with the Inter-University Council for East Africa based in Kampala, Uganda). He previously worked as Senior Technician and then Lecturer at the School of Information Sciences, Moi University. He has authored publications on e-learning, ICT policy and library resources.

$\mathrm{Mr}$ Ayoo is a member of Uganda Computer Society.

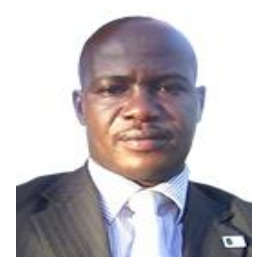

Jude $\mathbf{T}$ Lubega is a professor of information technology and also the Deputy Vice Chancellor of Uganda Technology and Management University (UTAMU). He graduated with a Bachelor's degree in Computer Science and Statistics from Uganda Martyrs University (UMU) in 2001. He further joined the University of Reading in England for his Masters in Network Centered Computing which he completed in 2002. He was awarded a scholarship for a Computer Science $\mathrm{PhD}$ in the University of Reading which he completed in 2006.

He has taught in the University of Reading between 2003 - 2006, in Makerere University between 2007 and 2012 and now teaching in UTAMU, where he is currently also the Deputy Vice Chancellor. He is an experienced ICT4D researcher, consultant and has undertaken numerous researches and projects both nationally and internationally. He is a member of several boards and has won several research funding awards to undertake ICT4D projects. $\mathrm{He}$ is a member of the ACM, BCS and Internet Society. He has published widely and has more than 45 publications in both journals and international conferences. He has been chair for the International Conference on Computing and ICT Research for the past 3 years. 